\title{
AC 2009-1599: LEADERSHIP 106: THE VALUE OF TIME
}

\section{Jerry Samples, University of Pittsburgh, Johnstown}

DR. JERRY SAMPLES holds a BS Ch.E. from Clarkson College, MS and Ph.D. in ME from Oklahoma State University. Dr. Samples served at the United States Military Academy twelve years before assuming the position of Director of the Engineering Technology Division at the University of Pittsburgh at Johnstown in 1996. After a five year period as the Vice President for Academic and Student Affairs he returned to the Engineering Technology Division. He is a Fellow of the International Society for Teaching and Learning receiving that honor in 2007. In 2008, he received the American Society for Engineering Education National Outstanding Teaching Award. 


\title{
Leadership 106: The Value of Time
}

\begin{abstract}
:
Time has a value because the supply is finite and the demand for it seems limitless; especially for faculty in the tenure-stream. If one thinks about it scientifically, the Second Law of

Thermodynamics has been related to the direction of time, a positive direction, and since no one exceeds the speed of light, then everyone is in a positive time warp. This simply means that time marches on and there is nothing that can be done about it other than use it effectively. Thus, the value of time is measured in such vague ways as time wasted, time effectively utilized and personal time.
\end{abstract}

The direction of this paper, positive in time, is to determine ways to eliminate the wasted time in order to effectively utilize time so that there is more personal time. The motivation for this paper was a small group of new faculty, approximately 10, who were discussing how much they value time in their new jobs and how others seem not to value their time. The concern being, how do they demonstrate that time is valuable? The immediate answer was productivity, including: publications, grants, graduates, and status in the discipline. All of these were in the effective category but there were a series of topics in the wasted category that may not belong there. These topics were time wasters only to the new faculty but did have value in their long term position as an educator: i.e. professional seminars, discipline specific meeting, and topics such as teaching. Finally, there were concerns that there was not enough personal time and that the stress from this alone caused reduced effectiveness in many cases.

This paper will discuss the categories of wasted, effective and personal time and give examples of how to optimize the categories such that waste is virtually eliminated. This sounds like a violation of the Second Law of Thermodynamics but it will become clear that it is the choice of the system being analyzed that allows for apparent efficiency increases without waste.

\section{Introduction:}

The motivation of this paper was the discussion of a small group of new faculty, approximately 10 , but is based on conversations with over 400 relatively new faculty at teaching seminars across the country. The mix of faculty in the larger sample represents the full range of institutions; teaching colleges to research universities. The 10 faulty member discussion group brought the topic to the forefront, thus stimulating the development of the material presented in this paper. The topic is important and has been alluded to in teaching books over the years ${ }^{2-4}$.

It is interesting to note that almost every faculty member encountered in over 25 years of higher education experience has concerns about time. They feel that there is not enough time to get everything accomplished including combinations of the following: teaching, research, service, meetings, grant writing, proposal writing, family time, and personal time. The competition for the scarce resource that time represents causes anxiety, frustration, and at times, depression. One of the main time sinks is the computer. With its advent came a myriad of new distracters of which email and web-surfing are the main time sinks. Time is an interesting resource, and it is time that needs to be optimized to resolve the concerns of the faculty. 


\section{Theory:}

Efficiency is defined in many ways in engineering depending on the discipline. As applied to an automobile engine it is the desired effect as compared the input cost: simply stated, the work out divided by the energy input or the work produced per unit of fuel energy consumed. It is common knowledge that the efficiency of an automobile engine is less that that of an ideal (Carnot) engine. It is similarly important to recall that the Carnot model for the heat engine requires that there be wasted energy and therefore the efficiency is less than $100 \%$. (Sorry, the athletic metaphor or giving $110 \%$ always causes goose bumps.) For the purposes of this paper a similar comparison will be made for time such that all time ( 24 hours per day) is compared to effective time with the appropriate wasted time. Thus, the efficiency will be the effective time divided by all time.

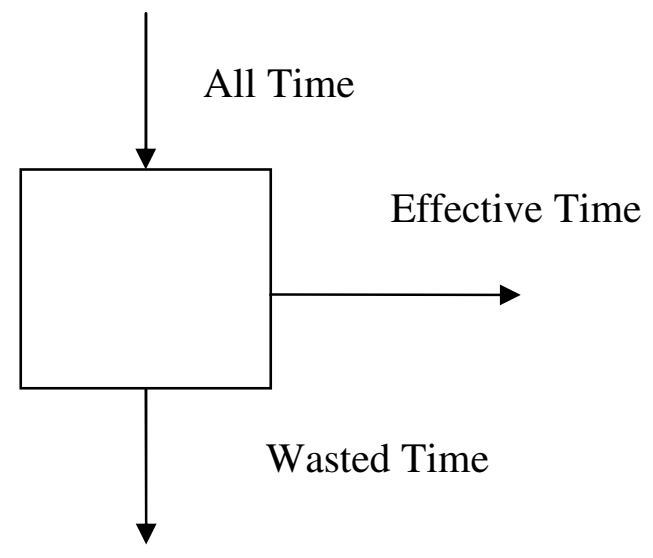

To understand the quantities utilized in the model there must be a definition of each quantity. It is important to understand that each person has a different definition of what times are effective and what times are wasted. As with the Carnot model for heat engines, any reduction in the wasted time transfers into higher gains - higher efficiency. Since the efficiency is being compared to all time, small reductions in wasted time will produce small increases in efficiency. It is now time to define wasted time and effective time since they will drive the solution of the problem. These are assumptions, if you will - just like the ones we use in problem solving.

\section{Definitions/Assumptions:}

The first step is to clearly define "All Time" as the entire 24 hour day. This is chosen since the period of time for such items as sleep, eating, exercise, and commuting are variables that cannot be estimated in this paper. Some people sleep less, others more. The same can be said of the other variables - so it is here that some people make room for more effective time and/or more wasted time. In a previous paper these basic functions accounted for approximately 10 hours per day ${ }^{1}$. As can be seen, these functions could account for nearly half of each day - leaving the maximum efficiency at 50\% - the Carnot limit on the efficiency of time to add perspective.

The "Effective Time" may include items such as: teaching, grant and proposal writing, journal and paper writing, discussions with peers, discussions with graduate students, basic research, meetings with research teams and research colleagues, and service requirements. Any of these can turn into "Wasted Time" without agendas or clear goals and time limits on topics of 
discussion. "Effective Time" can include time to de-stress, time for reflection, personal time, preparation of lists and agenda items, time to respond to questions about teaching or research, preparation of presentations, networking, and teaching graduate students how to operate in the work environment that is established. Of the "Effective Time" activities, new faculty agree that two are highly valued - research and publication - with an emphasis on teaching at some level. Then they ask why the rest of the activities are not listed as wasted time?

"Wasted Time" is the time that needs to be minimized to optimize every minute of the day. A transformation of 15 minutes of "Wasted Time" to "Effective Time" represents a 1\% increase in efficiency using our "All Time" model. One of the largest potential time wasters is the computer. Since the introduction of the computer, faculty members have taken over the tasks once left to others, such as secretaries. Faculty are now typing, retyping, wordsmithing, and spending numerous hours getting documents into perfect condition instead of relying on adequate writing. While expected, this constant reworking of every document takes many hours and often leads to marginal rewards. Email requires constant shifting of priorities because of multi-tasking. (We complain about student's lack of concentration - look at us.) A new message appears on the screen and it must be answered because those who send messages expect immediate turn-around of requirements. The days of reasonable suspense's have turned into expectations of immediate replies. And, messages not immediately answered may be lost in a list of documents that overshadow their priority - often for long periods of time - thus causing more stress when reminders come. Some faculty members think of teaching as a time waster because a mere satisfactory in teaching, with lots of journal publications, is enough for tenure; so why worry. Bad, ineffective teaching can be a time waster since students will require more time to gain an understanding of the material. Other "Wasted Time" includes meetings that are suddenly scheduled that are "good" for us. Some department meetings, lectures, and colloquia where attendance is expected stand in the way of planned activities from the "Effective Time" category. These activities are then thought as time wasters. The inability to say no to requirements makes faculty feel that these are of no value especially when compared to research and publication work. Other time wasters include: small time gaps between meetings, unexpected phone conversations, computer games, personal time, socialization at the coffee maker or in the halls, travel without internet connection - or with it, fear of writing, procrastination of any sort, unscheduled office calls by students and colleagues, and anxiety that stops faculty in their tracks.

The category not seen on the diagram above is "Personal Time." It appears as both an "Effective Time" and a "Wasted Time" depending on its application. In "Effective Time," "Personal Time" can be exercise, or family time spent to support a spouse or children in activities that build productive relationships. Such activities provide support at anxious moments and provide a sounding board when ideas are being kicked around. These activities can be de-stressors that actually recharge the batteries before the next task. "Personal Time" can also be moments when you just think and reflect on the positive aspects of life: sometimes you just have to stop and smell the roses ${ }^{4}$. It may also be time spent applying for positions, summer employment or a relaxing trip as a reward for good work. In "Wasted Time," "Personal Time" can be an excuse not to do things that are more important in a career sense. Computer games fall in this category as do long phone calls to friends, emails just to catch up, and any other "necessary" obligations that can wait but suddenly take priority. Inefficient use of "Personal Time" leads to excuses like 
being "brain-dead" or "exhausted' to the point of being ineffective. This is a vicious cycle and can lead to very poor production.

\section{"Wasted Time" resolution:}

So, the question is how can "Wasted Time" be eliminated thus producing nearly $100 \%$ efficiency? The answer is that it cannot! Looking at the model, it is apparent that some of "All Time" will always be included in "Wasted Time" because of the definition of "Effective Time." Since sleeping, eating and commuting, to name a few, are going to happen five days a week and the daily efficiency will be impacted by these "time wasters." Of course the upper limits of efficiency can be influenced if faculty sleep less, eat less and stay in the office instead of commuting. It is apparent that this is unrealistic because these modifications in biological needs usually cause lower, rather than higher efficiency in the long run. Commuting time will not usually change once the faculty member is settled. We will get back to these basic functions later in the paper.

The rest of the category of "Wasted Time" requires a little thought. Lowman", in a discussion of the teaching environment and time presents the following thesis:

"Faculty can be overworked, but they rarely are. More commonly, they feel overwhelmed by the variety of things expected of them - keeping up-to-date on the content of various courses, publishing good scholarship, becoming nationally conspicuous, preparing for and conducting good classes, meeting with students individually, supervising individual research projects, serving on committees. This is inherent in the job: college teaching offers tremendous freedom to structure time and channel energy, but it requires commensurate levels of internal motivation, personal organization, self-discipline, and ability to pursue multiple goals."

He goes on to say that faculty have a difficult time deciding how to spend their time and energy when it comes to their various requirements. He adds that:

"It is not the workload per se that most creates discomfort among college instructors but the necessity of deciding how to spend time. To borrow a thought from Erich Fromm (1941), anxiety is caused more by the freedom of college teaching than by its demands."

Not enough time can then be the excuse for poor teaching, poor scholarship, and disdain for collegial events (meetings and other service). McKeachie ${ }^{3}$ in discussing student learning states: “"'Time on task" is one of the most important principles (Chickering \& Gamson, 1987)." This same concept of time on task can be applied to faculty and is important to making "Wasted Time" become "Effective Time." So far, it appears that "Wasted Time" can be managed by being on task and removing anxiety through a structured approach. Such an approach is presented in the "Leadership $102^{1}$ " paper where Maxwell's 10 steps that lead to personal organization are presented, and include:

1. "Set Your Priorities."

2. "Place Priorities on Your Calendar." 
3. "Allow a Little Time for the Unexpected."

4. "Do Projects One at a Time."

a. "Organize each project in a folder."

b. "Itemize all that needs to be done."

c. "Prioritize in order of importance."

d. "Emphasize only one project at a time."

5. "Organize Your Workspace."

6. "Work According to Your Temperament."

7. "Use Your Driving Time for Light Work and Growth."

8. "Develop Systems That Work for You."

9. "Always Have a Plan for those Minutes Between Meetings."

10. "Focus on Results, Not the Activity."

Wankat and Oreovicz ${ }^{4}$ devote an entire chapter to efficiency which emphasizes the establishment of goals with the first being staying in good health followed by work goals and then rewards. As mentioned above, good health will contribute to efficiency and should be a primary concern.

They go on to make statements about establishing priorities. An easy way to establish priorities is a do-list. But be careful, if the first priority is overwhelming, then procrastination may set in or meaningless lesser priorities will sneak to the top of the list. This is a sure formula for increased anxiety and more procrastination. There are, of course, things that need to be inserted into the priority list on daily or weekly bases - such things as grading and being home for dinner. Each day there should be a list, reasonable in length, and with items that can be accomplished. Keep a separate, overall projects list for those things that are long term.

Next, since you have a list of priorities, establish times for working on each item for that day. You must be in charge of your time and since most meetings, classes and other normal functions are posted ahead of time you should be able to shape the rest of your day. Here is where you must manage those 15 to 30 minute periods to accomplish tasks that are important - to remove them from your list or to advance them to the next level of accomplishment. These periods are good times to make assignments to graduate students or make that phone call that needs to be made. Arranging ahead of time to meet with someone for a short discussion will accomplish two things - get the meeting done and have a hard time-hack for completion of the conversation. If you are busy during one of these times - tell colleagues and students that their interruptions need to come at a different time. Stand up and escort people to the door to hasten their departure and don't let them sit unless you want to be there a while. Controlling time is an important skill that should be learned. If socialization is important, always have an escape plan. Don't get involved in "can you top this story" sessions. Listen politely and then leave.

Next is that computer - the biggest time sink of all time. Don't play games - they do nothing but waste time and they are addictive. When writing, complete the task, print the material and edit it off-line. Then fix the edits and move on. The more times the manuscript is reviewed the more time that is wasted. If there is someone you trust, have them review your manuscript before going final. A word of caution - every time you ask someone to review something - they will reciprocate. This can be a huge time sink. Then there is email - which can easily consume an entire day - every day. The more list-serves that you are on, the more material you receive each more important than the last. When corresponding, keep it short. Use bulleted lists to 
respond to questions. Sometimes email is very convenient, especially during odd hours. Most of the time, the phone provides for understandable exchanges that can be very short. If you need a record of the conversation take notes or make a quick memorandum and file it, or keep a running daily log book with such annotations. Finally, presentation preparation can take a long time. While we all want to have beautiful slides, a decision needs to be made whether the time spent on slide shows is time well spent. Bottom-line on the computer - be careful that it is a tool, not the master of the day.

Meetings are an important part of any business and this is so in academia. Colloquia, meeting potential new colleagues, and attending meetings with decision makers are all important. But, some of the people who run these meetings are not as prepared as they should be. If possible, take something to read, take today's list, take a pad of paper and make progress on some project. While all time cannot be used at maximum efficiency, it can be used more effectively with some effort. Wankat and Oreovicz state that not all of our time is used efficiently but that some of our inefficiencies actually result in new ideas and progress.

Speaking of progress - there is one last time waster - travel. Travel takes time and tires out the traveler. After some number of trips our efficiency on such trips drops, our "hassle factor" goes way up and our interest goes down. Very few people can be efficient when they travel and most faulty who attend meetings agree that in three days there might be one or two good things that come to mind. Finding the optimum number of trips per year is important to the productivity and health of the faculty member - everyone must optimize on a personal basis.

It is clear at this point that "Wasted Time" needs to be reigned in. Some of this is accomplished by changing the way that each day is structured. Some changes require changes in the way we interface with colleagues and students. Some is just self-discipline that must be developed by every faculty member. Some is attitudinal - meetings may not be what we want to do but they are important. All "Wasted Time" will not be eliminated but some efficiency can be added that will assist in the optimization of output.

\section{Optimization:}

Let's return for a moment to the definition of the system, the concerns of the faculty and the reduction of waste. The definition of the system hinges on several assumptions: that "All Time" includes the nominal requirements of sleeping, eating, exercising and commuting; that "Personal Time" moves about depending on its contribution to productivity; and, that the system itself and the objectives of faculty positions are clearly stated. Any variation on one of these can change the overall efficiency of the system.

Looking first at the "All Time" category, it has been stated that certain items are difficult to predict and that they may change, not only from person to person, but also day to day. On the average, there is probably a number that can be chosen, for instance, 10 hours for sleep, etc. Of course we have all pulled all nighters, even as faculty, and know that this will certainly skew the data. There is one variation to "All Time" that could have a drastic impact on efficiency, that being the removal of this non-productive time from consideration, thus changing the category to "Available Time." See the diagram below. If this is done, every 15 minutes recovered from 
"Wasted Time" would result in a $1.8 \%$ increase in efficiency. While this feels good, it still reflects a 15 minutes savings and overall efficiency could be ridiculously high.

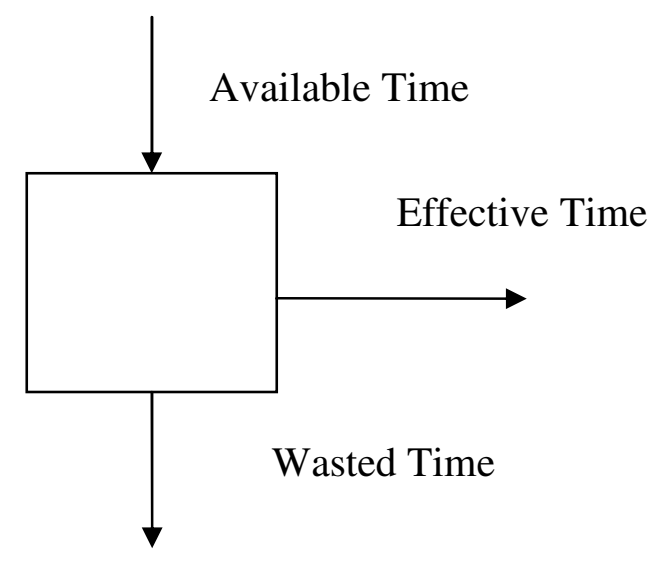

However, since the desire here is to show efficiency in a time constrained environment, it might be best to stay with "All Time" and keep the non-productive hours as waste since the model shows efficiency based on production - besides it is easier to account for every 15 minutes as equal to a $1 \%$ efficiency change.

"Personal Time" is very important and some leaders realize that family time and personal time are important to the over-all efficiency of the team. It is suggested that those items of "Personal Time' listed with "Effective Time" remain there since responsible faculty members will use it accordingly and still get their work accomplished. It is also obvious that some "Personal Time" is not well spent and therefore constitutes waste. It is proposed that faculty members carefully optimize the use of "Personal Time" to satisfy their personal good such that the impact is positive to the organization. This means that playing computer games, although relaxing, is not a good use of "Personal Time."

The remaining question is: What is "Wasted Time?" In academe, faculty members are hired to: teach, research, write, obtain funding, mentor graduate students and be collegial. Collegiality carries with it requirements to attend meetings, perform service, assist colleagues and enter into productive discussions on a wide variety of topics, and attend colloquia. With this as the description of the job for which one is hired, then none of these elements can be placed in "Wasted Time" in, and of themselves. What may waste time is the quality of some of these events, and in many cases there is nothing that a faculty member can do about this lack of quality. Here is where the inefficiencies described by Wankat and Oreovicz ${ }^{4}$ fit in. Taking along other things to do, think while the presenter is talking, write lists, outline a paper, write notes for graduate students, or do something personal. This becomes a win-win situation - you are there and you get some work accomplished. Thus, the wasted time becomes marginally efficient. Instead of losing $4 \%$, perhaps there is only a $2 \%$ efficiency loss.

Finally, plan the day and stick to the plan as much as possible. If the schedule gets too full, make decisions on what can be accomplished and cancel the rest. This is a good time to send that short email that says, "I can't make the meeting - sorry." Write down the time you waste be honest. Write down accomplishments - a "did list." Compare what was to be accomplished 
with what was done and devise a method to stay on task in the future. Also, review the wasted time list and devise a method to improve on that also. It is important to review the week and the month regularly. There will be times when it will be obvious that procrastination, time wasters, or the inability to say no, have impacted efficiency.

Finally, there is a need to change the attitudinal situation that appears to exist as a result of the priorities that faculty members receive from the administration. While there is great emphasis on research funding and publications at the administrative level - it is important to realize that the approval process for any positive career action goes directly through the faculty. It may be in vogue to think of so many committees and meetings as wasted time, but colleagues will consider collegiality when making recommendations for promotion and tenure to the administration.

\section{Conclusions:}

There are five things that must be done to achieve higher efficiency:

1. One must consider what the job really entails and then adjust attitudes to fit in. Basically, Lowman ${ }^{2}$ said it correctly when he addressed the workload of faculty.

2. Real "Wasted Time" needs to be eliminated so that more time can be placed on "Effective Time" and simultaneously on effective "Personal Time."

3. Lists need to be prepared to plan (do lists), assess accomplishments (did lists) and to monitor lost time ("Wasted Time" list).

4. Optimize items 1-3 to make the day more effective.

5. Learn what influences efficiency and take charge of these items. Remember, even a messy desk can impact attitude and efficiency.

\section{Bibliography:}

1. Samples, J. W., (2005) "Leadership 102 - Your First Team - The Research Group", 2005 American Society for Engineering Education Annual Conference Proceedings, Portland, OR.

2. Lowman, J. (1995). Mastering the Techniques of Teaching, Second Edition, San Francisco, CA Jossey-Bass. 3. McKeachie, W.J. (1999). Teaching tips: Strategies, research, and theory for college and university teachers, Tenth Edition, Boston, MA: Houghton Mifflin.

4. Wankat, P.C. and Oreovicz, F.S. (1993). Teaching Engineering, New York: McGraw-Hill, Inc. 